\title{
Clases de armas $y$ armas de clase: hachas metálicas en conjuntos funerarios argáricos
}

\section{Classes of weapons and weapons of class: metal axes in Argaric funeral assemblages}

\begin{abstract}
Hace mucho tiempo que nos conocemos, Emili, unos más que otros, pero siempre ha existido entre nosotros una gran amistad y respeto. Nos ha tocado enseñar e investigar en universidades diferentes e interesarnos por épocas distintas de la prehistoria. Las circunstancias nos llevaron a profundizar en las formas de violencia en la prehistoria y más concretamente en las armas y fortificaciones que se idearon para materializarla. Tú, Emili, en el mundo ibérico y nosotros en El Argar, topamos con las formas más sofisticadas de la ingeniería bélica y de la arquitectura militar. Sin embargo, hay un tema que nos vincula y no es otro que el repudio a toda forma de violencia social, física, psíquica, estructural o simbólica. Por todo esto, hemos escogido este texto para dedicártelo.
\end{abstract}

Los ajuares funerarios del grupo arqueológico argárico constituyen una fuente excepcional para conocer la organización sociopolítica de esta sociedad de inicios de la Edad del Bronce. El presente artículo se centra en el análisis de las tumbas que incluyen hachas metálicas como parte de las ofrendas, una práctica datada en la última fase de desarrollo argárico (1800/1750 - 1550 cal ANE). El análisis de los datos disponibles permite confirmar algunas de las hipótesis sociológicas planteadas al respecto por nuestro equipo, y avanzar nuevas perspectivas de conocimiento. En síntesis, la similitud estructural entre los ajuares funerarios con hacha y los previos con alabarda refuerza la clasificación de las primeras como armas. Sin embargo, en términos sociales sus portadores pertenecieron a una clase social distinta a la de los alabarderos, en el cuadro de disimetrías propio de los últimos siglos argáricos. Finalmente, la excepcional concentración de tumbas con hacha en el yacimiento de El Argar vincula el ejercicio de la violencia física a nuevas formas de dominio político a escala regional.

Palabras clave: El Argar, armas prehistóricas, hacha, alabarda metalurgia, Edad del Bronce.
Argaric grave goods provide an exceptional source of knowledge as to the sociopolitical organization of society in the Early Bronze Age. The present article focuses on analysing the burials containing metal axes among their grave goods, a practice dating to the last phase of the Argaric Culture (1800/1750-1550 cal BCE). The analysis of the available data confirms some of the sociological hypotheses put forward by our team as well as advancing new prospects of gaining knowledge. In short, the similarity between the assemblages of grave goods comprising axes and earlier halberds bolsters the notion of the earlier objects as weapons. However, in the context of the asymmetries characteristic of the last centuries of the Argaric period, the bearers of axes must have belonged to a social class differing from that of those with halberds. Finally, the great concentration of burials containing axes at the site of El Argar links the practice of physical violence to new forms of political control at a regional scale.

Keywords: El Argar, prehistoric weapons, axe, halberd, metallurgy, Bronze Age. 


\section{Introducción}

Las prácticas funerarias argáricas supusieron un notable esfuerzo para la población, al amortizar un trabajo social que dejó de revertir económicamente en la misma. Los intereses ideológico-políticos dieron sentido al gasto implicado en estas ceremonias, en las que hombres, mujeres y niños o niñas recibieron al morir tratamientos diferentes según su ubicación previa en lugares sociales determinados por edad, sexo y/o clase. La política funeraria no solo manifiesta patrones conductuales que tratan de asegurar cierta forma de convivir, sino que reparte los papeles que les merecen distintos "tipos" de personas en ese espectáculo de cohesión social (Lull 2017).

El objetivo de este texto es profundizar en el vínculo entre el valor social de los objetos incluidos en tumbas argáricas con hachas de cobre o bronce, y la consideración política de las personas asociadas ritualmente a estas (Lull y Picazo 1989; Lull 2000a). A este respecto, revisaremos y actualizaremos las hipótesis planteadas en investigaciones previas (Lull y Estévez 1986; Castro et al. 1993-1994) a la luz de nuevos datos y, por otro lado, ensayaremos líneas de trabajo inéditas sobre los conjuntos funerarios con presencia de hacha.

Dar con el lugar político de quienes fueron enterrados con hachas y esbozar su emplazamiento en la estructura social argárica, exigía desarrollar una investigación sobre el campo de evidencias que acompañaba a estos ítems. A tal fin, inventariamos los contextos funerarios en que aparecían, definimos sus características, revisamos el valor social relativo de sus ajuares y tratamos de confirmar la supuesta disimetría entre estas sepulturas y las que acogían miembros de la clase dominante, tanto coetánea como de la época precedente. ${ }^{1}$

\section{Alabardas frente a hachas en la estructura social argárica}

En diversos estudios centrados en las alabardas argáricas, propusimos que estos ítems correspondían a las élites dirigentes (Lull y Estévez 1986; Castro et al. 1993-1994; Lull y Risch 1995; Lull 2000b). Las alabardas materializaron la necesidad coercitiva de un dominio social estable y consumaron, debido a ello, la primera producción de armas a escala social de la prehistoria reciente de la península ibérica. En estas investigaciones planteamos que su amortización en contextos funerarios se limitó a un estadio preciso del desarrollo de la sociedad argárica, durante al menos los siglos xx y xIx cal ANE (Lull et al. 2017a). Además, detectamos una asociación recurrente entre alabarda y puñal, ${ }^{2}$ lo que permitió sugerir un sistema

1. Como hemos propuesto en diversas ocasiones (véase Lull et alii 2009) el desarrollo argárico, grosso modo, puede establecerse en tres fases: Fase I: 2200-2000/1950 cal ANE, Fase II: 2000/1950-1800/1750 cal ANE y Fase III: $1800 / 1750-1550$ cal ANE.

2. A partir de ahora, utilizaremos las siguientes abreviaturas para una serie de objetos argáricos: ALB (alabarda), HAC (hacha), PÑ (puñal o cuchillo), BZ (brazalete), PD (anillo, pendiente o espiral); en cuanto a los yacimientos: AR (El Argar), de combate basado en el uso combinado de estas dos armas (Lull et al. 2017b).

En la actualidad, no hay nuevos datos que modifiquen la datación de alabardas en contextos funerarios durante la Fase II argárica (ca. 2000-1800 cal ANE), ni tampoco su adscripción exclusiva a los hombres que ostentaban el dominio social. Aunque haya diferencias entre las tumbas de "alabarderos", sus ajuares suelen respetar la asociación ALB+PÑ, una porción de fauna, preferentemente de ganado bovino, y uno o dos recipientes cerámicos. Si tenemos en cuenta que, cuando se documenta un par de recipientes, estos parecen formar parte de un mismo juego (un vaso grande, contenedor principal, y otro pequeño, escanciador de contenido), la asociación entre ALB y un recipiente o un juego de dos sería altamente significativa. Además, aproximadamente la cuarta parte de estas tumbas incluye oro o plata en forma de adornos (BZ o PD). Otra característica de estas tumbas es que en algunas ocasiones se depositaron instrumentos de trabajo (cinceles, yunques o afiladores). Además, un porcentaje relativamente alto de alabarderos ocupaban tumbas dobles junto a una mujer. ${ }^{3}$ En los casos en que disponemos de información estratigráfica y cronométrica, la tumba siempre fue inaugurada por un cadáver femenino, mientras que el masculino fue depositado años después.

En términos de distribución geográfica, las alabardas se documentan en todo el territorio argárico, ${ }^{4}$ tanto en asentamientos de altura como de llano. Podría decirse que las portan pocos hombres, pero en todas partes. ${ }^{5}$

OF (El Oficio), FA (Fuente Álamo) y GT (Gatas), en Almería; AY (La Almoloya), CG (Cabeza Gorda), IF (Ifre) y MM (Madres Mercedarias, en el casco urbano de Lorca), en Murcia; CA (Castellón Alto), CE (Cerro de la Encina), TR (Terrera del Reloj), en Granada y LC (Laderas del Castillo), en Alicante. En cuanto a La Bastida (Murcia), se utilizan distintas abreviaturas según la tumba citada provenga de una u otra de las excavaciones llevadas a cabo por diversos agentes desde finales del siglo XIX (BAS: L. Siret y P. Flores; BAC: J. Cuadrado Ruiz; BAO, Seminario de Historia Primitiva del Hombre, dirigido por J. Martínez Santa-Olalla; BA: campañas recientes a cargo de la Universitat Autònoma de Barcelona).

3. El $44 \%$ de las tumbas con alabarda e información antropológica $(\mathrm{N}=36)$ son dobles (Lull et alii 2017b: tabla 1), por encima de la media entre las necrópolis argáricas (Lull et alii 2016: 36, tabla 1).

4. Aun así, es interesante señalar que casi el $90 \%$ de las alabardas halladas en el territorio argárico proceden de yacimientos situados en las comarcas litorales y prelitorales entre el noreste de Almería y el sur de Alicante.

5. Las alabardas están presentes en sepulturas suficientemente documentadas de El Argar (15), El Oficio (5), Fuente Alamo (5), La Almoloya (3), Las Herrerías (2), Los Cipreses (1), Cabecico de los Moros (1), Gatas (1), Hoya del Matadero (1), Puntarrón Chico (1), El Rincón de Almendricos (1), Castellón Alto (1), El Tabayá (1), La Bastida (1) y Laderas del Castillo (1). Las 39 sepulturas que las contenían se reparten entre 14 yacimientos. Solo conocemos una sepultura del interior del sureste, en Castellón Alto, con un contexto funerario documentado, mientras que otras alabardas de yacimientos también del interior carecen de él (Puebla de Don Fadrique, Deifontes, El Zalabí, entre otros casos). En el exterior del territorio argárico, hay alabardas de filiación o tipología argárica hasta el norte peninsular nunca lejos de la costa mediterránea (Tossal de l'Abeller y Tossal del Mortòrum, en Castellón), y hasta el oeste, en el bajo Guadalquivir (Setefilla, en Sevilla). 
Una primera aproximación a la estructura social de la sociedad argárica entre ca. 2000 y 1800 cal ANE sugiere que las alabardas serían el indicio de una oligarquía masculina que ostentaría el control en sus asentamientos en el marco de una red de relaciones entre iguales. Que existiera o no un primus inter pares, se nos escapa. No obstante, apunta a ello la combinación de dos condiciones. La primera, necesaria, es la constatación de pares. En este sentido, a la vista de la reiteración de alabardas en ciertos lugares como El Argar, El Oficio, Fuente Álamo o La Almoloya, es muy probable que conviviesen en un mismo asentamiento varios individuos con análogo estatus político. Aun así, no parece obligado pensar solo en conjuntos de pares a escala local. La segunda condición viene dada porque algunas tumbas destacan por un mayor valor social amortizado, ya sea en forma de adornos de oro o plata (AR-244, AR-1025, FA-1, FA75 y OF-62) o por el mayor trabajo invertido en la elaboración del contenedor funerario (AR-994, AR-1024, FA-1 y AY-80). En conjunto, sugerimos el funcionamiento de una oligarquía a diferentes escalas, local o comarcal-regional, a la hora de dar cuenta en términos políticos de estas evidencias de distinto signo.

Si bien la alabarda puede ser considerada el ítem distintivo y diagnóstico de la clase dominante de la Fase II, no cabe, en principio, afirmar lo mismo para las hachas. Estos ítems sustituyeron a las alabardas como elementos de ajuar masculinos de la Fase III, ${ }^{6}$ pero no es evidente que lo hiciesen en iguales condiciones. Ello se debe a que el hacha "convivió" con otros dos ítems que la superaban en rango de significación: la espada larga y la diadema, ambos denotadores de la clase dominante de esa época (Lull y Estévez 1986: 450). Las espadas se asociaban exclusivamente a hombres, mientras que las diademas lo fueron respecto a mujeres.

Espadas y diademas pertenecen a la categoría de mayor rango debido a la conjunción significativa de dos circunstancias: su presencia en el conjunto de las sepulturas argáricas es muy escasa pero, cuando aparecen, están acompañadas de un número considerable de materiales de calidad y metales nobles. ${ }^{7}$ El peso de espadas y diademas desplazó al hacha a un lugar secundario dentro de la pirámide de valores sociales que uno de nosotros propuso a mediados de la década de 1980 (Lull y Estévez 1986). A la vez, sirvió para establecer que el binomio HAC+PÑ componía el ajuar normativo básico de los hombres de pleno derecho (tercera categoría de ajuar), dejando la combinación $\mathrm{PZ}+\mathrm{PN}$ para las mujeres de su misma clase (Lull y Estévez 1986: 450). La revisión de

6. Los hermanos Siret propusieron lo contrario, es decir, que las alabardas sustituyeron a las hachas (1890: 264, 343 ; 1888: 49). Posteriormente, Blance (1971), Schubart (1973) y Lull (1983) manifestaron la precedencia temporal de las alabardas, y Castro et alii (1993-1994: 91-97) lo confirmaron mediante el primer programa sistemático de dataciones radiocarbónicas.

7. Las espadas largas y las diademas de plata son características de la Fase III. El escaso número de espadas en contextos funerarios documentados (AR-429, AR-824, FA-9 y CG-1) destaca la calidad de los ítems que atraen. Lo mismo ocurre con las diademas de plata (AR-51, AR-62, AR-398, AR454, OF-6, GT-2, FA-9 y AY-38). las características de las sepulturas con hacha y su dispersión geográfica permite actualmente matizar esta cuestión.

\section{Las hachas "funerarias"}

Acabamos de señalar que la investigación de Lull y Estévez (1986) sobre las categorías sociales argáricas concluyó que los ítems de la clase dominante se deslindaban estadísticamente de los ajuares de las sepulturas con hacha, situando a sus ocupantes en la categoría inferior de "miembros de pleno derecho de la comunidad" (Lull y Estévez 1986: 451). Este estudio se basó en las características de los contenedores funerarios y la composición de los ajuares de una muestra formada por 396 tumbas individuales con registro completo, gran parte de ellas del yacimiento de El Argar. En aquellos momentos se disponía de muy pocas determinaciones osteológicas, por lo que las piezas de ajuar más relevantes no pudieron asociarse con seguridad a parámetros de sexo y edad.

Años después, a mediados de la década de 1990, la disponibilidad de un primer conjunto de identificaciones antropológicas y de varias dataciones radiocarbónicas (Castro et al. 1993-1994: 96-97) permitió certificar la estrecha asociación entre individuos masculinos y hachas, así como su posterioridad en el ámbito funerario respecto a las alabardas. En la actualidad, el incremento en hallazgos arqueológicos y análisis científicos, así como el acceso a la documentación de campo de las excavaciones de la familia Flores y los hermanos Siret, abren nuevas posibilidades de conocimiento. Como hemos avanzado, las investigaciones recientes confirman el depósito funerario de alabardas durante la Fase II argárica, mientras que el de las hachas se registró en la Fase III. Igualmente, se ha certificado la asociación exclusiva de ambas armas respecto a individuos masculinos. Tan solo una sepultura en urna hallada en 1945 en La Bastida (BAO-37) plantea reservas, ya que contenía un hacha y un punzón, ítems mutuamente excluyentes ${ }^{8}$ con una adscripción sexual opuesta. Las referencias publicadas en su día mencionan solo un adulto (Posac et al. 1947: 118), pero los escasos restos óseos identificados en los fondos del Museo Arqueológico de Murcia matizaron que era un individuo adolescente, fallecido entre los 12 y 14 años (Fregeiro y Oliart 2015: 1525). Podría pensarse que se trataba en realidad de una tumba doble inadvertida como tal, si bien las escuetas informaciones de campo solo mencionan un cráneo situado en el fondo de la urna (Posac et al. 1947: 100-101; del Val y Sopranis 2015: 691; Lull et al. 2015a: 781-782). Aun así, la observación de que "el esqueleto no estaba en la posición original" (Posac et al. 1947: 100; del Val y Sopranis 2015: 691) y que el hacha se encontraba en una posición extraña, encima del cráneo con el filo hacia arriba, no permite descartar la posibilidad de algún tipo de alteración.

8. Esta asociación solo se ha documentado en tumbas dobles que contenían un hombre y una mujer, por lo que el punzón pudo corresponder al individuo femenino. 
Cuando el hacha aparece en tumbas dobles, la presencia de un cadáver masculino y de otro femenino es característica. ${ }^{9}$ Solo en un caso se documentó la asociación entre un hombre y un individuo infantil $(\mathrm{CA}-121) .{ }^{10}$

En total, contamos con 80 hachas halladas en tumbas de todo el territorio argárico, repartidas en diez ubicaciones (figura 3). El elevado número de hachas en el yacimiento de El Argar (59 sepulturas) es particularmente llamativo, puesto que esta cantidad convierte casi en anecdótica la presencia de estos ítems en las tumbas de los otros nueve enclaves. ${ }^{11}$ La primera constatación destacable es que solo una de cada cuatro hachas se ha documentado fuera del yacimiento de El Argar. Podría objetarse que esta abundancia es atribuible a que también aquí se ha excavado el mayor número de sepulturas. Sin embargo, la relación entre tumbas descubiertas y hachas en contexto funerario alcanza niveles de significación estadística a favor de El Argar cuando comparamos sus cifras con las de El Oficio y La Bastida, los yacimientos que le siguen en frecuencia de hachas. En suma, parece clara la prevalencia de El Argar respecto a los demás asentamientos, de hecho en una medida mayor que la que mantenía en la Fase II respecto a las alabardas, cuando "solo" el $40 \%$ de las piezas con contexto conocido se halló en el yacimiento de Antas. Podemos sugerir, por tanto, que las hachas funerarias se concentran significativamente en El Argar, mientras que las alabardas, no.

Las diferencias entre ambos objetos se extienden a los tipos de contenedor funerario en que aparecen. Así, en el yacimiento de El Argar el $80 \%$ de las alabardas apareció en cistas, ${ }^{12}$ mientras que el $96 \%$ de las hachas lo hizo en urnas. $^{13}$ En los restantes yacimientos, la relación entre hachas y urnas varía considerablemente aunque, en conjunto, la mayoría respeta esta asociación (65\%), muy por encima de fosas/covachas $(20 \%)$ y cistas (15\%). Esta constatación podría indicar que la normativa ritual de las hachas en el asentamiento de El Argar fue más estricta que en otros lugares.

El protagonismo de El Argar en la correlación hacha-urna nos obligó a seguir dos itinerarios para averiguar si era debida a circunstancias cronológicas, sociales o a ambas. Sabíamos que la adscripción de

9. Es excepcional el hallazgo en La Bastida (BA-18) de una tumba con un hacha y dos hombres adultos jóvenes (Lull et alii 2016: 48-50).

10. La sepultura 17 del sector Madres Mercedarias (MM-17), en el casco urbano de Lorca, fue vinculada con un hombre y un infantil (Martínez Rodríguez y Ponce 2002: 129), debido a un error en la transcripción del informe realizado por J. Buikstra y C. Rihuete Herrada para el Museo Arqueológico de Lorca en 1994. En este informe consta que, en realidad, la tumba contenía dos adultos de sexo indeterminado, uno fallecido a una edad superior a 35 años y otro entre 25 y 30 años.

11. El Oficio (7), La Bastida (6), Fuente Álamo (1), Ifre (1), Lorca (1), Laderas del Castillo (1), Terrera del Reloj (1), Cerro de la Encina (1), Castellón Alto (1).

12. Solo se ha documentado una alabarda en urna (AR-575), concretamente de la variedad Montejícar, muy poco frecuente (Schubart 1973).

13. No alcanza el $100 \%$ porque el contenedor de una sepultura (AR-387) está descrito de forma confusa en los cuadernos de campo de Flores, y AR-427 es una tumba en fosa. las cistas a la Fase II y de las urnas a la Fase III no era absoluta y directa, sino probabilística, al igual que ocurría con las preferencias geográficas por uno u otro tipo de contenedor funerario. ${ }^{14}$ De ahí que fuese necesario determinar, en primer lugar, la cronología respectiva de alabardas y hachas para contrastar la hipótesis de la substitución ritual de las primeras por las segundas. Como ya hemos mencionado, en la década de 1990 iniciamos un programa de datación radiocarbónica de ajuares funerarios argáricos, uno de cuyos resultados apuntó a que las hachas sucedieron a las alabardas a partir de ca. $1800 \mathrm{cal}$ ANE (Castro et al. 1993-1994). En la actualidad, a la luz de las nuevas dataciones y gracias a observaciones estratigráficas en nuestras excavaciones en La Bastida y La Almoloya, ${ }^{15}$ continuamos proponiendo que las alabardas dejaron de ser utilizadas en las prácticas funerarias en torno a la fecha indicada, consolidándose su sustitución por hachas hacia mediados del siglo XvIII cal ANE. Queda claro que las tumbas con alabarda no pertenecían al mismo mundo que las tumbas con hacha, lo cual invita a profundizar en los cambios rituales y materiales que conllevó dicha sustitución.

El primer análisis concierne a las personas armadas, entre las que no hay un solo caso documentado de sexo femenino. ${ }^{16}$ Los individuos masculinos con hacha en el yacimiento de El Argar corresponden, sorprendentemente, a todos los rangos de edad. ${ }^{17} \mathrm{~A}$ los alabarderos, en cambio, el arma les era asignada mayoritariamente si fallecían bien entrada la edad adulta $(57 \%)$ o ya senil (30\%); a este respecto, solo un $13 \%$ de las alabardas acompañan cadáveres de adultos jóvenes, y ningún individuo menor de 20 años pareció merecerlas. Cabría plantear, por tanto, que la alabarda era adquirida por méritos, al menos entre un sector de la población masculina, mientras que el hacha era susceptible de ser adscrita a ciertos individuos independientemente de que hubiesen sido capaces siquiera de utilizarla convenientemente. Así, en las tumbas de El Argar con información de edad ( $n$ $=42$ ) el $14 \%$ de las hachas acompañaba a infantiles,

14. La preferencia por fosas y cistas en el interior del territorio argárico contrasta con la utilización mayoritaria también de cistas pero, especialmente, de urnas en el área nuclear litoral y prelitoral (Lull y Estévez 1986: 444-446).

15. Lull et al. $(2015 b, c)$. Pese a los graves problemas en el laboratorio de datación de la Universidad de Kiel, podrían aceptarse las tres dataciones coincidentes obtenidas a partir de muestras de semillas de cebada depositadas en una de las vasijas de ajuar de BA-18 (KIA-40099: 3405 20 BP, KIA-40100: $3400 \pm 20$ BP, KIA-40100-2: $3410 \pm 62$ BP) (Lull et al. 2015d: tabla 1). El cenotafio BA-13, que incluía un hacha, se depositó en el mismo nivel estratigráfico que BA-18.

16. Kunter (1990) estimó que los restos de mandíbula, dientes sueltos y huesos de pie de AR-885 correspondían a un individuo posiblemente femenino fallecido a los 15 años (1990: 33). La revisión de estos materiales conservados en los Museos Reales de Arte e Historia de Bruselas permite precisar, a partir de la morfología del mentón y del estado de erupción y atrición dental, que se trataba de un posible varón adulto joven (20-35 años).

17. El total de tumbas con hacha que cuentan con información sobre la edad de fallecimiento del o de los inhumados es de 41 , casi un $70 \%$ de la colección. 
incluso menores de dos $\operatorname{años}^{18} \mathrm{y}$, por inferencia, muy probablemente de sexo masculino, ${ }^{19}$ mientras que otro $10 \%$ acompañó a adolescentes..$^{20}$ Este $24 \%$ de infantiles y juveniles no hubiera podido recibir un arma en la liturgia funeraria de El Argar de haber vivido en la fase precedente, ni siquiera perteneciendo a la clase dominante. La información disponible para el resto de yacimientos es insuficiente y desigual, ${ }^{21}$ aunque vuelve a destacar la escasa representación de individuos seniles ${ }^{22}$ frente a una clara mayoría de adultos jóvenes (menores de 35-40 años), algún adolescente ${ }^{23}$ e incluso un cenotafio. ${ }^{24}$ Sobre esta cuestión, es interesante señalar que las hachas que acompañaban a todos los individuos subadultos corresponden a los grupos de tamaño pequeño $(\mathrm{P})$ o muy pequeño (MP) según el análisis estadístico realizado por Lull, ${ }^{25}$ cuyas principales conclusiones se mantienen al restringir la muestra a los ejemplares hallados en tumbas. Ello refuerza la connotación simbólica, al menos en el yacimiento de El Argar, entre las hachas y la condición social adscrita a determinados individuos desde una edad muy temprana. En suma, ello refrendaría algunas intuiciones formuladas hace tiempo (Lull 1983: 455; Lull y Estévez 1986; Lull 2000b) y manifestaría la extensión de las relaciones hereditarias más allá de la élite (Lull et al. 2005).

Hasta aquí hemos subrayado las diferencias entre individuos armados de una y otra fase en cuanto al tipo de tumba que los contenía y a la edad de fallecimiento en que se manifestaba la amortización funeraria. Estas diferencias, en cambio, no se extienden a la estructura básica del ajuar. Así, si sustituyéramos en un ejercicio mental las alabardas por las hachas en las tumbas de la Fase II, no observaríamos cambios relevantes en los restantes ítems que las acompañarían. Para desarrollar esta cuestión, partiremos solo de las tumbas individuales con hacha o con alabarda y utilizaremos las tumbas dobles cuando ello sea posible sin desvirtuar el resultado. Además, dado el predominio cuantitativo de las hachas funerarias del yacimiento de El Argar, lo usaremos como referente en primera instancia a la hora de comparar hachas con alabardas.

De las 59 sepulturas con hacha del yacimiento de El Argar, 48 eran individuales y 11 dobles. En el caso de las alabardas, de las 39 tumbas suficientemente

18. AR-810 contenía un individuo infantil de entre 12 y 18 meses.

19. Se trata de las sepulturas AR-387, AR-427, AR-732, AR810, AR-822 y probablemente también AR-949.

20. Tumbas AR-35 (12-16 años), AR-434 (14-20 años), AR-768 (14-21 años) y AR-849 (15-18 años).

21. Desafortunadamente, solo disponemos de datos sobre edad de fallecimiento para 12 de las 21 sepulturas con hacha documentadas fuera del yacimiento de El Argar.

22. Únicamente representados por OF-238 (9\%), en consonancia con los resultados de la serie de El Argar (12\%) y en claro contraste con los porcentajes registrados entre los alabarderos, donde los individuos seniles representan el 30\% de la colección.

23. BAO-37.

24. BA-13.

25. Lull (1983: 181). Conviene señalar que, si bien los individuos subadultos fueron inhumados con hachas pequeñas, no todas las hachas pequeñas acompañaron a individuos de esta clase de edad. documentadas que las contenían, 20 eran individuales, 16 dobles; de las 3 restantes no disponemos de datos fiables. En primer lugar, se repite la asociación recurrente con el PÑ. La asociación HAC+PÑ se da en un $79 \%$ de las sepulturas, un porcentaje casi idéntico al de ALB+PÑ (82\%). En lo que respecta a la cerámica, 45 de las 48 tumbas individuales de El Argar $(93,7 \%)$ contienen algún vaso. Es interesante que suela depositarse un solo recipiente $(79 \%) .{ }^{26}$ Por su parte, la cerámica se documenta en un $90 \%$ de las tumbas individuales con alabarda, proporción equivalente a la de las hachas, aunque en aquellas solo el $60 \%$ contenía un vaso. La posibilidad de que los dos vasos que acompañaban a las alabardas formaran parte de un mismo juego (contenedor y escanciador), como señalamos anteriormente, incrementaría la similitud con el ajuar cerámico de las hachas. ${ }^{27}$ Si tomamos en consideración todas las tumbas con alabarda, individuales y dobles $(\mathrm{N}=39)$, el porcentaje con cerámica se eleva hasta el $92 \%$, casi idéntico al de las hachas.

De entre las tumbas con hacha documentadas fuera del yacimiento de El Argar, el 89\% contenía algún recipiente cerámico, una cifra próxima a la ofrecida por El Argar en solitario. Sin embargo, si restringimos el cálculo a las tumbas individuales, el porcentaje baja al $66,6 \%$, y todavía más, hasta el $42 \%$, si consideramos la presencia de un solo vaso. Así pues, y tal y como sucedía con el tipo de contenedor funerario, cuando nos alejamos de El Argar la norma funeraria aplicada a los individuos masculinos con hacha parece tornarse menos estricta.

En el yacimiento de El Argar, los adornos que acompañan tanto a alabardas como a hachas son generalmente $\mathrm{BZ}^{28}$ y PD. ${ }^{29}$ La mayor cantidad de adornos en las tumbas con hacha es destacable, ${ }^{30}$ como también lo es la presencia de oro solo en las primeras. ${ }^{31}$ La proporción de adornos de metal es

26. Solo tres de las 48 tumbas tienen dos vasos $(6,25 \%)$ : AR-580, AR-822 y AR-816 (en esta última uno de los vasos estaba en el exterior).

27. Se trata de un vaso grande y otro pequeño, en ocasiones uno dentro del otro. Los contenedores grandes son de F6 o F5 y, los pequeños, en su mayoría de F5.

28. Diecisiete tumbas individuales contenían brazaletes (35\%), siempre de cobre o bronce; en un caso, dos ejemplares (AR$816)$. Esta cifra aumenta a $24(40,7 \%)$ si añadimos las tumbas dobles. En las tumbas con alabarda, los brazaletes pueden ser también de oro o plata, aparte de cobre.

29. Veinticinco tumbas individuales contenían aros o espirales de metal en forma de pendientes o anillos, simples o de varias vueltas. Podía llevarse solo uno (10 tumbas) o un par (12), aunque en alguna ocasión se documentaron tres (AR-816), cinco (AR-822) o hasta seis (AR-580). Estos datos aseguran que el $66,66 \%$ de las tumbas individuales con hacha contenían PD. Si consideramos las tumbas dobles, la proporción de PD se mantiene $(63,63 \%)$ aunque la cantidad de adornos por sepultura sea un poco más del doble a favor de las tumbas dobles, y es que estos ornamentos se asocian a hombres y mujeres por igual.

30. Se documentan en un $66 \%$, frente al $17 \%$ de las tumbas con alabarda. Destaca igualmente el mayor porcentaje de adornos en plata (25\%) si lo comparamos con la presencia de este metal en las tumbas con alabarda (13\%). Sin embargo, ello puede deberse a la relativamente tardía y progresiva generalización de la plata en el territorio argárico.

31. Todas ellas en Fuente Álamo (FA-1, FA-18 y FA-75) 
casi idéntica. ${ }^{32}$ En cambio, si dejamos a un lado las sepulturas con hacha del yacimiento de El Argar, la correlación cambia en cuanto a los $\mathrm{BZ}^{33}$ y $\mathrm{PD},{ }^{34}$ básicamente en lo que se refiere a las tumbas individuales, que ahora contienen menos BZ y PD que las de El Argar. La diferencia más llamativa concierne a los PD, ya que los individuos con hacha de El Argar portaban el doble que los del resto del territorio.

En cuanto a la presencia de plata, las tumbas individuales de El Argar (27\%), dobles (18\%) o ambas en conjunto $(25 \%)$ presentan valores inferiores a las de los restantes yacimientos (individuales: 50\%; dobles: 50\%; en conjunto: $48 \%$ ), una circunstancia hasta cierto punto inesperada que por el momento solo cabe enunciar.

Las ofrendas de porciones de fauna aportan otro matiz diferenciador. En las sepulturas con alabarda este tipo de ofrendas es bastante común, tanto en inhumaciones individuales $(65 \%)$ como en dobles $(69 \%)$. Por su parte, en las tumbas con hacha disminuye en ambas clases de contextos (37\% en tumbas individuales y $47 \%$ en dobles). Es destacable que, hasta donde hemos podido averiguar, los restos de ganado bovino son más frecuentes en las tumbas con alabarda. ${ }^{35}$

En suma y como conclusión empírica, los enterramientos con hacha acostumbran a ser individuales (81\%), cuentan significativamente con un PÑ (79\% de los casos), por lo general con una pieza cerámica, un BZ y PD, en ocasiones, y en la mitad de los casos, alguna ofrenda cárnica.

\section{El sistema de combate con hacha}

Las escasas diferencias estructurales entre los ajuares de las sepulturas con alabarda o con hacha pueden explicarse, en buena medida, por la distancia cronológica que los separa. Ni siquiera hay diferencias apreciables en cuanto a la posición de ambas clases de armas en relación con los cuerpos. A diferencia de las tumbas con alabarda, para las que se dispone de un pequeño grupo de casos con documentación

32. El $24 \%$ en las tumbas con hacha, frente al $26 \%$ en las tumbas con alabarda.

33. El $24 \%$ de las individuales contiene BZ; la proporción sube al $33,3 \%$ si incluimos las dobles.

34. El 38\% de las individuales tienen PD, un porcentaje que sube hasta el $62 \%$ si incluimos todas las sepulturas.

35. Investigaciones recientes en el Museo Arqueológico Nacional (Madrid) y en los Musées Royaux d'Art et d'Histoire (Bruselas) (Andúgar et al. 2018-e.p.) indican que, si bien las tumbas con porciones de fauna son habituales en sepulturas que contienen alabardas o hachas, las características de esta clase de ofrenda se diferencian cuantitativa y cualitativamente. En este sentido, su frecuencia relativa difiere sustancialmente: $64 \%$ en tumbas con alabarda, frente a $30 \%$ en sepulturas con hacha. De manera similar, aunque compartan el gusto por porciones de las mismas especies (exclusivamente ganado bovino y ovicaprino) la asociación de bovinos con alabarderos es ligeramente más intensa que la que se documenta respecto a las hachas (36\% frente a $19 \%)$. Un dato interesante es que en la sepultura AR-810, donde se inhumó a una criatura de entre 12 y 18 meses, se documentó la panoplia guerrera característica $(\mathrm{HAC}+\mathrm{PN})$ junto a una porción de bovino, un vaso de Forma 5 y un collar con un colgante de diente de jabalí, emulando en sus características el ajuar completo de un adulto. arqueológica reciente y detallada, el conocimiento sobre la ubicación de las hachas se deriva de representaciones efectuadas en excavaciones antiguas, salvo en tres casos. ${ }^{36}$ Las representaciones a que nos referimos son, principalmente, textos y croquis que Pedro Flores y alguno de sus hijos plasmaron en cuadernos de campo siguiendo instrucciones de los hermanos Siret. ${ }^{37}$ La virtud de estos documentos es que sitúan los objetos de cada tumba en el punto aproximado donde aparecieron, además de resaltar algún detalle significativo como, por ejemplo, su morfología aproximada, y el número y disposición de los remaches en puñales, cuchillos y alabardas. Dichos detalles no solo han servido para identificar algunas piezas cuya procedencia se había perdido en fondos museísticos, sino también para comenzar a investigar la existencia o no de pautas en la disposición ritual de distintos tipos de ofrendas. En estos valiosos apuntes, las hachas se representan casi siempre a ambos lados o encima de la cabeza, o bien a la altura del tórax. Ello sugiere que, al igual que las alabardas, las hachas eran depositadas en posición de parada, muy próximas o en contacto con hombros, brazos, pecho y cara, o bien en posición de descanso, sujetas a la espalda.

Si bien la ubicación de alabardas y hachas en las tumbas es similar, el sistema de combate basado en unas y otras ofrece importantes diferencias. Si nos atenemos a sus características intrínsecas, las hachas mejoran la capacidad ofensiva de las alabardas. Quizá la diferencia más notable resida en que el hacha tiene estabilidad suficiente para ser arrojada, lo que le confiere un suplemento letal del que carecía la alabarda. ${ }^{38}$ Además, aunque ambas sean armas contundentes, el hacha supera a la alabarda al añadir la capacidad de cortar y, en parte, tajar, a la capacidad compartida de penetrar. Por otro lado, el mango del hacha debía ser tan corto como el de la alabarda o incluso más; ${ }^{39}$ si no fuera así, no hubiese cabido en alguna de las sepulturas donde han sido halladas.

Es notorio que el hacha presenta un problema que no tenía la alabarda y que atañe a su funcionalidad. Probablemente, las hachas se usaran también como herramientas. ${ }^{40}$ Otra característica que podría influir

36. Tanto en BA-18 (Lull et al. 2015b) como en BAO-37 (Posac et al. 2017: 100-101; del Val y Sopranis 2015: 691) y en FA-69 (Schubart 2012: 133) el hacha estaba muy probablemente a la espalda. En FA-68 y BAO-37 apareció cerca de la cabeza y en BA-18 se deslizó hacia el dorso del guerrero.

37. Los cuadernos que contienen estos registros se conservan en el Museo Arqueológico Nacional (Madrid) <http://www.man. es/man/coleccion/catalogos-tematicos/siret.html $>$.

38. No es sencillo acertar a media distancia con un hacha y, además, un lanzamiento fallido deja cuando menos parcialmente desarmado al atacante. Respecto a la posible longitud del mango, las referencias para hachas de cobre o bronce son escasas. Una de las hachas con orificio de enmangue hallada en la Necrópolis Real de Ur (mediados del III milenio cal ANE) conservaba un mango completo de $47 \mathrm{~cm}$ de longitud (Woolley 1934: 305).

39. Por sus pequeñas dimensiones, en algunas tumbas infantiles debió ser inviable depositar el hacha enmangada. Se abre, con ello, un interesante dilema entre utilidad y funcionalidad, entre donación y ofrenda, entre objeto y valor simbólico, y entre objeto y valor social.

40. De las 97 tumbas inequívocamente masculinas (sumando sepulturas con alabardas y hachas), si clasificamos hachas y 
en una supuesta bifuncionalidad es que el cabezal metálico puede enmangarse de dos maneras distintas, lo cual afecta a su uso de manera notable. En términos convencionales, las hachas cuyo filo guarda la misma alineación respecto al mango son consideradas hachas propiamente dichas, mientras que cuando el filo es transversal o perpendicular respecto a la dirección del movimiento, se habla de azuela. De las primeras, encontramos bastantes evidencias. ${ }^{41}$ En cambio, es difícil documentar indicios inequívocos de las segundas. La sepultura 121 de Castellón Alto ilustra, al parecer, esta posibilidad (Molina et al. 2003). En cualquier caso, una azuela también podría ser un arma letal. El problema reside en que es menos "fluida" para procurar un área defensiva rotando por braceo, a causa de la dificultad de mantener el filo en una posición potencialmente hiriente.

La "filosofía" del hacha como arma reside en el ataque y la agresividad. Parece que exijan un escudo como complemento, pero cuando en lugar de ello se combina con un puñal o daga, como sucede en El Argar, se hacen patentes sus carencias porque resulta poco adecuada para la defensa. Es notable también la fragilidad del portador después de un golpe fallido o para resguardarse tras cada ataque, un inconveniente compartido con la alabarda.

El sistema de combate no solo concierne a los aspectos vinculados con el manejo individual de un arma concreta o de una panoplia completa, sino que incluye las formas de coordinación y acción entre combatientes de cada bando. Y, a su vez, este último aspecto guarda una relación estrecha con la organización sociopolítica que recluta y mantiene al grupo de combatientes.

\section{El lugar social de los guerreros en la Fase III}

Los alabarderos de la Fase II eran, al tiempo, guerreros y gobernantes. La violencia física que ejercieron tuvo que ver con la expansión territorial argárica hacia el interior peninsular, así como con el mantenimiento de los privilegios que ellos mismos disfrutaban. La distribución geográfica de sus tumbas sugiere un control territorial casi ubicuo o capilar al menos en las comarcas argáricas nucleares, dado que se las localiza tanto en asentamientos de altura de distinta extensión (Fuente Álamo, El Oficio, La Bastida, La Almoloya) como en aldeas de zonas bajas (El Rincón de Almendricos, Los Cipreses, Herrerías). Esta dispersión territorial no contradice la existencia de concentraciones destacadas de alabarderos en ciertos asentamientos (El Argar) ni tampoco cierta preeminencia por parte de algunos

puñales como armas las herramientas solo aparecen en seis (6\%). Ello lleva a pensar que lo que se realzó en el orden simbólico no fue la faceta instrumental.

41. En las láminas publicadas por Siret y Siret (1890), cuando se observan huellas del enmangue siempre se trata de líneas oblicuas cerca de la base o talón (AR-48, AR-116, AR-400, AR479, AR-497, AR-572, AR-605, AR-639, AR-654, AR-703, AR-768, AR-771). En un caso, se ha conservado un mango de madera con un orificio rectangular para insertar el talón (AR-572). de estos individuos (primus inter pares). El cuadro de conjunto dibuja una clase de guerreros-gobernantes, capaces de mantener el dominio sobre sus territorios combatiendo en pequeños contingentes o, llegado el caso, individualmente, y, a la vez, capaces de tejer alianzas lo bastante extensas y sólidas como para emprender expediciones de conquista.

Sin embargo, la situación en la Fase III ofrece un panorama diferente. Por un lado, la excepcionalmente alta concentración de hombres con hacha en el asentamiento de El Argar evoca una clara centralidad en cuanto al ejercicio de la violencia física. Ahora bien, en estos momentos sus protagonistas conformaban un colectivo subordinado, por debajo de una clase dominante demarcada en el ritual funerario masculino por un arma nueva y ventajosa, la espada. A título de hipótesis, sugerimos que los portadores de hacha formaban parte de destacamentos armados especializados, a las órdenes de una élite dominante muy restringida en número, característica de la fase argárica reciente. Sus bases no se hallaban distribuidas ampliamente por el territorio, como sucedía con los alabarderos, sino que estaban centralizadas en la depresión de Vera (El Argar, El Oficio) y, subsidiariamente, hacia el norte en algún punto del valle del Guadalentín (La Bastida). Desde estos enclaves surorientales pudo ejercerse el control político y económico cuando menos sobre un amplio territorio de las comarcas litorales y prelitorales del sureste. Quedaría por ver si dicho dominio alcanzó las regiones del interior y las zonas de frontera donde, curiosamente, parecen ser más frecuentes las espadas que las hachas.

Tal vez, estos guerreros que portaban hachas se ajustasen más a la imagen de los hoplitas que tenemos del mundo griego de época clásica. Estos hombres no pertenecerían a la clase dominante, pero tampoco a una clase desposeída y a sueldo de aquella. Más bien, serían miembros de una clase propietaria que manifestó en el ritual funerario el derecho a transmitir hereditariamente su riqueza y condición, tal y como sugieren las tumbas de subadultos con hacha. Esta idea de guerreros "hoplíticos" no tiene por qué ser original de la Grecia clásica. La infantería armada con hachas representada en el Estandarte de Ur (mediados del III milenio cal ANE) (Woolley 1934: 305, lám. 91) podría ser un temprano ejemplo ilustrativo.

\section{Producción y circulación de las hachas argáricas}

Desgraciadamente, la composición química de las hachas nada aporta en relación con su probable bifuncionalidad herramienta/arma. En varias ocasiones los hermanos Siret reiteran que todas las hachas son de cobre (Siret y Siret 1890: 183, 275, 341) basándose en análisis químicos de hachas procedentes de sepulturas o de fuera de ellas. ${ }^{42}$ Dado que al hacha de la sepultura AR-554 le acompañaba un PÑ con un contenido del 6,54\% de estaño, los Siret podrían haber sugerido que las hachas no requerían de ese

42. IF-2 o AR-693, en el caso de las funerarias (Siret y Siret 1890: 275), halladas fuera de las sepulturas (Siret y Siret 1890: $341)$. 


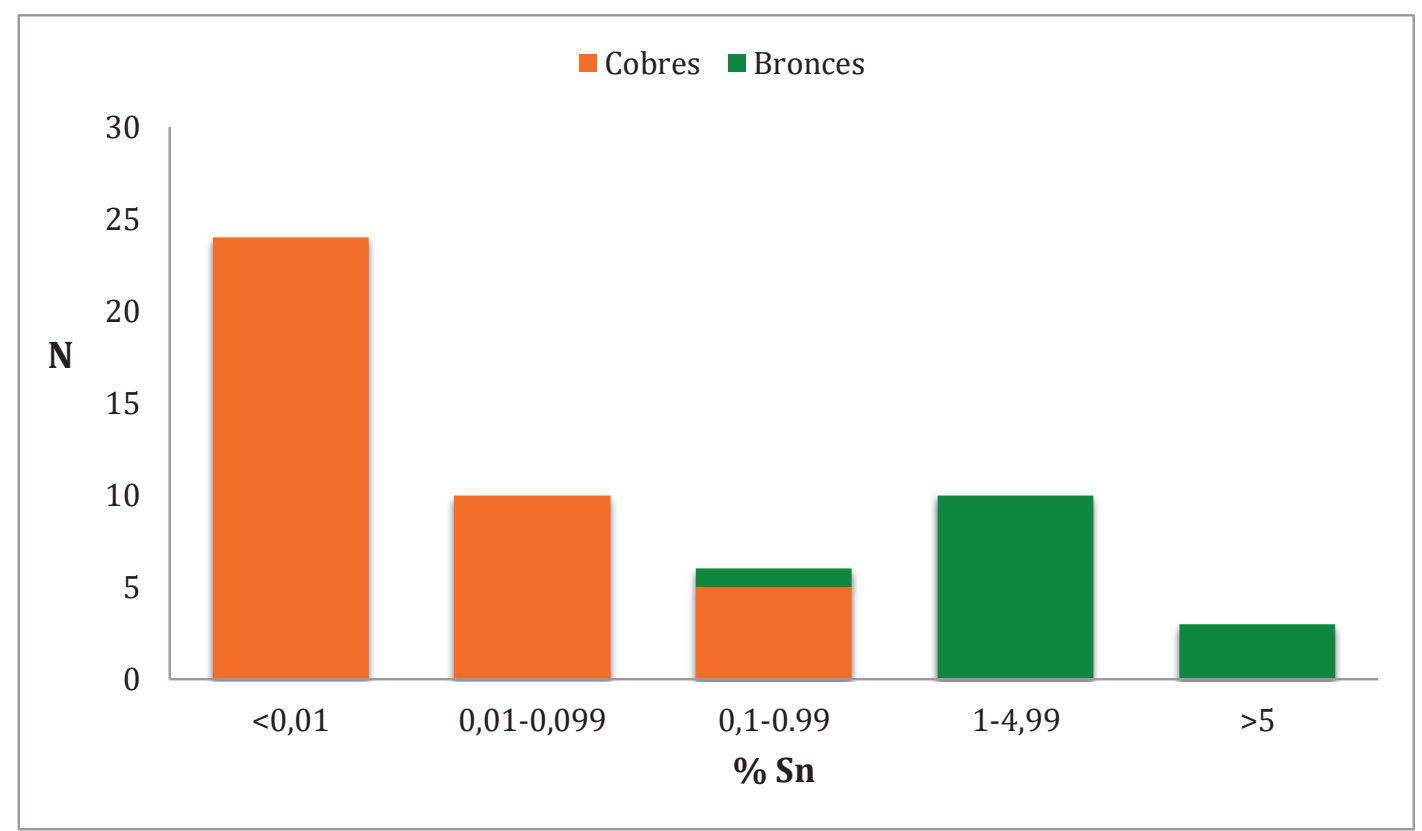

Figura 1. Presencia de estaño en las 53 hachas argáricas con contextualización más o menos segura. Los análisis fueron realizados por diferentes equipos a lo largo de los siglos xx y xxI. (Junghans et al. 1960 y 1968; Harrison y Cradock 1981; Schubart y Arteaga 1986; Hook et al. 1987; Arribas et al. 1989; Rovira et al. 1997; Simón 1998; Müller-Kissing 2014; Montero et al. 2014; Murrillo-Barroso et al. 2015).

componente que, en cierta medida, enriquecía el PÑ subsidiario (Siret y Siret 1890: Tabla III, 275-6). Sin embargo, no lo hicieron, quizá debido a que el análisis de otra muestra de hacha sin contexto, localizada en las inmediaciones de la Cueva del Agua, dio estaño en una proporción aún mayor $(8,26 \%)$. Es notorio que los objetos con una buena proporción de estaño se documentan en el tramo final de El Argar, aunque la funcionalidad de las hachas no se flexibilizó con ello. De los 53 análisis químicos más o menos fiables que se han realizado después de los estudios pioneros de los hermanos Siret, casi una cuarta parte muestran composiciones de más de $1 \%$ de estaño, pudiendo clasificarse como bronces de baja aleación ${ }^{43}$ (figura 1). El valor más alto de estaño documentado hasta el momento corresponde al 8,28\% del hacha de la tumba 17 de Madre Mercedarias (Montero et al. 2014). En cuanto a las variables cronológica y espacial de las hachas con estaño, se avala su cronología reciente mientras que la distribución espacial no distingue ninguna preferencia regional, pues aparecen en yacimientos de todo el territorio argárico (Tabayá, San Antón, Monteagudo, Lorca, El Oficio, El Argar, Castellón Alto y El Zalabí).

Aunque tanto el estaño como el arsénico permiten producir objetos mas resistentes, ambos elementos tienen una distribución de frecuencias muy diferente (figuras 1 y 2). Ningún ejemplar presenta menos de

43. Spindler ya hablaba en 1971 de bronces de "baja aleación" para los que contienen entre 0,126 y 4\% de estaño. Apuntaba que son característicos de los momentos en los que se empezaba a introducir el bronce en una zona, lo cual parece una premonición de lo que sucedió en la última fase de El Argar. Para Pernicka (1998), el término "bronce" debería aplicarse a todo objeto de cobre con más del 1\% de estaño. c. $0,1 \%$, ni más de c. 3,7\% de arsénico. En general, parece observarse una tendencia a producir hachas con 1-2\% de arsénico, proporción que resulta algo inferior a la detectada en cuchillos y alabardas (Montero 1994: 260; Lull et al. 2010: 327). Por otra parte, la presencia de arsénico tiende a ser algo menor en las hachas de bronce, tal y como cabría esperar si ambos elementos resultasen intercambiables en el plano mecánico. En definitiva, los análisis químicos disponibles sugieren un patrón de fundición común de las hachas, en el que únicamente se introduce el estaño en detrimento del arsénico hacia finales del periodo argárico.

En cuanto a la producción de las hachas, tanto las caracterizaciones química e isotópica como la presencia en algunos poblados de moldes y hachas sin acabar de forjar, sugieren la existencia de diversos centros de fundición y acabado dentro y quizás incluso fuera del territorio argárico. Mientras el hacha de la tumba FA69 fue realizada con mineral procedente de alguno de los depósitos de las sierras litorales de Almería o Murcia, ${ }^{44}$ otras piezas se ajustan mejor a las composiciones de las mineralizaciones de sierra Morena. Recientemente se ha analizado el hacha de la tumba 18 del Cerro de la Encina, Granada, y sus valores isotópicos no parecen coincidir con ninguna de las mineralizaciones del sureste peninsular detectadas hasta el momento (Murillo-Barroso et al. 2015). En este caso, el cobre arsenical utilizado para su fabricación podría proceder de distritos mineros situados más al oeste del territorio argárico.

La presencia de moldes con matrices de hacha en contextos de cronología argárica está confir-

44. A ello apuntan la composición química y los valores isotópicos (Lull et al. 2017c). 


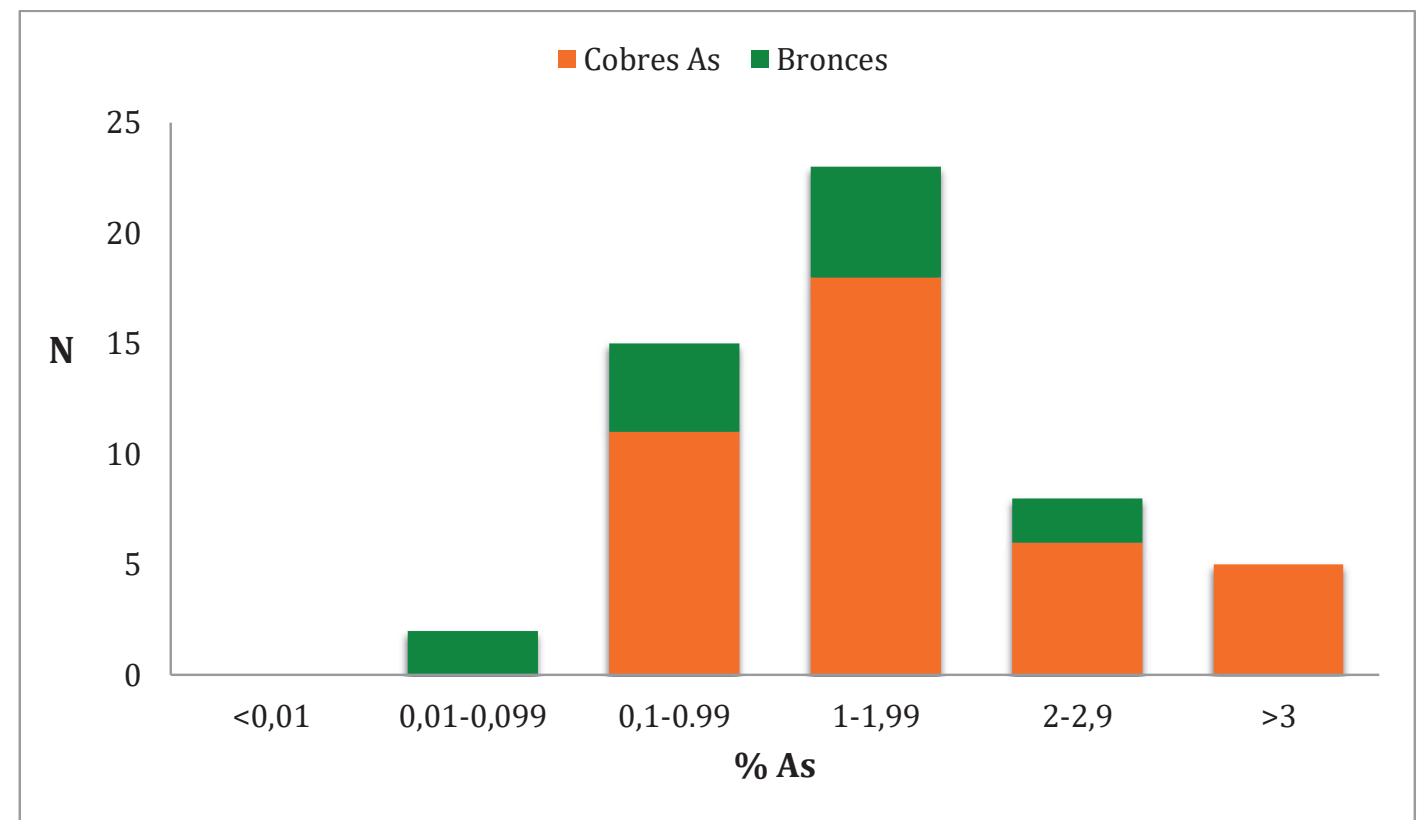

Figura 2. Presencia de arsénico en las 53 hachas de cobre arsenical y estannífero analizadas químicamente.

mada en El Argar, La Bastida, La Almoloya, Lorca, Bagil, Tabayá, Cerro de la Virgen, Cuesta del Negro y, sobre todo, Peñalosa (Lull et al. 2010 y 2015c). Los moldes encontrados en otros poblados, como El Oficio o Gatas, pueden ser argáricos o pertenecer a momentos posteriores, cuando las actividades metalúrgicas se hicieron más comunes (Delgado-Raack y Risch 2008). También, cabe mencionar un hacha con rebabas de fundición, aparecida cerca de la tumba 108 de Fuente Álamo (Pingel et al. 1998: 31).

Por último, en cuanto a los instrumentos macrolíticos relacionados con la forja y el pulido del metal, solo algunos asentamientos se dedicaban a ello (Risch 2002), mientras otros eran abastecidos de piezas que debían ser acabadas mediante dichos trabajos de forja y pulido. En definitiva y a la vista de las siempre esquivas evidencias arqueometalúrgicas del grupo argárico, podemos señalar que la fundición, el forjado y la circulación de hachas de metal eran más amplios, al menos en y entre los grandes poblados de altura, de lo que sugiere su presencia en las tumbas de la última fase — con la notable excepción de El Argar. Tras las motivaciones de este sesgo ritual entre producción y práctica funeraria posiblemente se encuentre una de las claves para entender la especificidad política e ideológica del propio asentamiento de El Argar.

\section{Conclusiones}

A lo largo de este trabajo nos hemos centrado en las implicaciones arqueológicas y sociológicas que ofrecen las sepulturas argáricas con presencia de hachas de cobre o bronce. No partíamos de cero, sino de varias hipótesis planteadas desde la década de
1980, según las cuales las hachas reemplazaron a las alabardas hacia $1800 \mathrm{cal}$ ANE en el registro funerario, siempre en asociación con individuos masculinos. La disponibilidad de nuevos datos arqueológicos y analíticos, así como la aplicación de enfoques diversos ha permitido apoyar en buena medida aquellas, así como sugerir inferencias inéditas.

- Se confirma la sucesión alabarda-hacha en torno a la cronología indicada. También, la vinculación de hachas a individuos masculinos, con el matiz de que estos podían merecerlas a cualquier edad, mientras que las alabardas previas se reservaban a adultos, preferentemente de edad avanzada.

- Los ajuares con presencia de hacha resultan análogos, estructuralmente hablando, a los que antes incluían alabarda. Esta semejanza aporta un argumento indirecto, pero significativo, a favor de la consideración como armas de las hachas depositadas en las tumbas, y en contra de su significado como útiles de trabajo.

- La sustitución alabarda-hacha en el plano estructural-arqueológico no guardó correspondencia en el plano estructural-social. Los alabarderos encabezaban la pirámide social de su época, mientras que quienes portaban hacha eran miembros de una clase capaz de transmitir hereditariamente derechos de propiedad y de condición social, aunque subordinada a una clase dominante muy restringida, denotada arqueológicamente por espadas y diademas.

- La distribución geográfica de las tumbas con hacha sugiere una marcada centralización del poder militar en la depresión de Vera y, sobre todo, en El Argar. Ello pudo ser síntoma de una creciente centralización política respecto a la fase anterior. 
V. Lull, R. Micó, c. Rihuete Herrada, R. Risch, Clases de armas y armas de clase: hachas metálicas en conjuntos funerarios argáricos

\section{Agradecimientos}

Vicente Lull

Las investigaciones contenidas en este artículo han lubio@arrakis.es sido desarrolladas al amparo del proyecto "Genealogías y redes en El Argar" (MICINN, HAR2017-85962-P) y Rafael Micó han contado con la ayuda de la AGAUR - Generalitat de Catalunya (2017SGR1044). María Inés Fregeiro, Camila Oliart y Miguel Valerio aportaron valiosos comentarios que nos han incitado a una mayor precisión. Vaya para ellos nuestro agradecimiento.

\section{Cristina Rihuete Herrada} cristinarihuete@gmail.com

Roberto Risch robert.risch@uab.cat

Departament de Prehistòria, Universitat Autònoma de Barcelona 
V. Lull, R. Micó, C. Rihuete Herrada, R. Risch, Clases de armas y armas de clase: hachas metálicas en conjuntos funerarios argáricos

\begin{tabular}{|c|c|c|c|c|c|c|}
\hline Tumba & Tipo & Sexo/Edad (años) & Armas/Útiles & Adornos & Cerámica & Fauna \\
\hline \multicolumn{7}{|c|}{ El Argar - Tumbas individuales } \\
\hline AR-0001 & F4 & 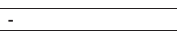 & HAC & & F4 & \\
\hline AR-0005 & F4 & $\mathrm{H}>20$ & HAC PÑ & & F2 & $\mathrm{F}$ \\
\hline AR-0026 & F4 & & HAC PN & & F8b & \\
\hline AR-0035 & F4 & H 12-16 & HAC PN & BZ PD & F4 & \\
\hline AR-0038 & F4 & & HAC PN & $2 \mathrm{PD}$ & $\mathrm{F} 4$ & \\
\hline AR-0048 & F4 & $\mathrm{HAd}$ & HAC PN & $\mathrm{BZPD}^{*}$ & F5 & \\
\hline AR-0069 & $\mathrm{F} 4$ & $i ? 20-30$ & HAC PÑ & 2PD COLL(2) & F5 & \\
\hline AR-0116 & F4 & H $30-40$ & HAC PN & BZ & F4 & \\
\hline AR-0139 & F4 & - & HAC PN & & F1 & \\
\hline AR-0208 & F4 & - & HAC PN & $2 \mathrm{PD}^{*}$ & F5 & \\
\hline AR-0212 & F4 & $i ? 30-50$ & HAC PN & & & \\
\hline AR-0307 & F4/F2? & -.0000 & HAC PN & PD & F7s & $\mathrm{F}$ \\
\hline AR-0373 & F4 & - & HAC PN & BZ PD PD* COLL(18) & $\mathrm{F} 4$ & $\mathrm{~F}$ \\
\hline AR-0387 & FOSA? & Infantil * & HAC PN & & F2 & $\mathrm{F}$ \\
\hline AR-0400 & F4 & $H ? 50-60$ & HAC PN & BZ PD PD* & $\mathrm{F} 4$ & \\
\hline AR-0408 & $F ?$ & $H$ ? $40-50$ & HAC & & & \\
\hline AR-0427 & FOSA? & Infantil * & HAC & & & \\
\hline AR-0434 & F4 & $i ? 14-20$ & HAC PÑ & & F1 & \\
\hline AR-0479 & F4 & $\mathrm{H} ?>30$ & HAC PN & $2 \mathrm{PD}^{*}$ & F2 & $\mathrm{F}$ \\
\hline AR-0497 & F4/F4? & & HAC PN & PD & F4 ext & $\mathrm{F}$ \\
\hline AR-0513 & F4 & $\mathrm{H}$ ?? 20-40 & HAC PN & $2 \mathrm{PD}$ & F5 & $\mathrm{F}$ \\
\hline AR-0554 & F4 & $H ? 20-40$ & 2HAC PN & BZ & F5 & \\
\hline AR-0572 & F4 & $i ? 20-30$ & HAC & & F5 & \\
\hline AR-0580 & F4 & $\mathrm{H} 25-30$ & HAC PÑ & BZ 4PD 2PD* $\operatorname{COLL}\left(11+1^{*}\right)$ & F5/F8a & \\
\hline AR-0585 & F4/F4? & & HAC PN & & F5 & $\mathrm{F}$ \\
\hline AR-0605 & F4 & $\mathrm{H}>50$ & HAC & & $\mathrm{F} 4$ & \\
\hline AR-0632 & F4 & & HAC & & F7s & \\
\hline AR-0639 & F4/F4? & H 25-35 & HAC PN & & F2 & $\mathrm{F}$ \\
\hline AR-0654 & F4 & H 25-35 & HAC PN & $\mathrm{BZ} \mathrm{PD}^{*}$ & F1 & $\mathrm{F}$ \\
\hline AR-0673 & F4 & $\mathrm{H}>50$ & HAC PN & & $\mathrm{F} 4$ & \\
\hline AR-0693 & F4 & $i ? 30-40$ & HAC PN & PD & & $\mathrm{F}$ \\
\hline AR-0703 & F4 & $\mathrm{H}$ ? 30-50 & HAC PN & BZ PD & F7s & $\mathrm{F}$ \\
\hline AR-0725 & F4 & $\mathrm{H}$ ? 40-60 & HAC PN & $\mathrm{BZ}_{2} \mathrm{PD}^{*} \mathrm{COLL}(22)$ & F4 & $\mathrm{F}$ \\
\hline AR-0732 & F2B3y & Infantil & HAC & & F4 & $\mathrm{F}$ \\
\hline AR-0746 & F4 & $\mathrm{H}$ ?? 20-30 & HAC & PD PD* COLL(15) & F2 & $\mathrm{F}$ \\
\hline AR-0752 & F4 & - & HAC PN & PD & F2 polip. & \\
\hline AR-0768 & F4 & $i ? 14-21$ & HAC PN & $\mathrm{BZ} 2 \mathrm{PD}^{*}$ & F1 & \\
\hline AR-0771 & F4 & - & HAC PN & $2 \mathrm{PD}^{*}$ & $\mathrm{~F} 4$ & $\mathrm{~F}$ \\
\hline AR-0784 & F4 & $i ? 30-50$ & HAC PN & PD & F1 & \\
\hline AR-0799 & F4 & & HAC & $\mathrm{PD}$ & & \\
\hline AR-0810 & F4 & $1-1,5$ & HAC PN & 2PD COLL(?) & F5 & $\mathrm{F}$ \\
\hline AR-0816 & F4 & $i ? 20-40$ & HAC PÑ & 2BZ 3PD & F4/F1ext & $\mathrm{F}$ \\
\hline AR-0822 & F1/F1? & Infantil * & HAC PN & BZ 4PD PD* COLL(?) & F1/F7s & \\
\hline AR-0849 & F4 & H 15-18 & HAC PN & $\mathrm{BZ}$ & F1 & $\mathrm{F}$ \\
\hline AR-0862 & F4 & $i ? 20-40$ & HAC PN & $\mathrm{BZ}$ & F5 & $\mathrm{F}$ \\
\hline AR-0885 & F4 & H? 20-35 & HAC PN & $\mathrm{BZ}$ & $\mathrm{F} 4$ & \\
\hline AR-0949 & F5 & Infantil? * & HAC PN & & & \\
\hline AR-0952 & $\mathrm{F} 4$ & $i ? 20-30$ & HAC PN & COLL(?) & F1 & \\
\hline \multicolumn{7}{|c|}{ El Argar - Tumbas dobles } \\
\hline AR-0021 & F4 & $\begin{array}{l}\text { H 40-60 } \\
\text { F 40-60 }\end{array}$ & HAC 2PÑ & BZ COLL(28) & F4/F8a & $\mathrm{F}$ \\
\hline AR-0189 & F4 & & HAC PÑ & BZ 3PD COLL(38) & F4/F7s/F8a & \\
\hline AR-0245 & F4 & $\begin{array}{l}H>50 \\
F 30-40\end{array}$ & HAC PÑ & BZ PD 2PD* COLL(2) & $\mathrm{F} 1 / \mathrm{F} 2$ & $\mathrm{~F}$ \\
\hline AR-0538 & F4 & $\begin{array}{l}\mathrm{H} ? 20-30 \\
\mathrm{~F} 20-35\end{array}$ & HAC PÑ & COLL(11) & F2/F5 & \\
\hline AR-0609 & F4 & $\begin{array}{l}\mathrm{H}>50 \\
\mathrm{~F} 25-30\end{array}$ & HAC PÑ & COLL(24) & F2/F8a & \\
\hline AR-0813 & F4 & $i ? 30-50$ & HAC 3PÑ & $\mathrm{BZ}^{\star} 3 \mathrm{PD}^{\star} \mathrm{COLL}(6 ?)$ & F4ext & $\mathrm{F}$ \\
\hline AR-0940 & F4/F4? & - & HAC PÑ & $2 \mathrm{PD}$ & F5/F8a/F4ext & \\
\hline AR-0958 & F4 & $i ? 30-50$ & HAC PÑ & BZ 3PD & F4/F8a & $\mathrm{F}$ \\
\hline AR-0968 & F4 & $\mathrm{H}$ ?? 40-60 & HAC & BZ PD & F4/F8a & \\
\hline AR-0977 & F4 & $\begin{array}{l}\mathrm{H} \text { ? }>20 \\
\mathrm{~F} ? 20-40\end{array}$ & HAC PÑ & BZ 4PD COLL(53?) & F5/F8a & \\
\hline AR-0984 & F4 & $\begin{array}{l}\text { H } 30-40 \\
\text { F } 15-25\end{array}$ & HAC & & F2/F7s/F8a & \\
\hline \multicolumn{7}{|c|}{ Otros yacimientos - Tumbas individuales } \\
\hline BAS-1 & F2B3y & - & HAC & & & $\mathrm{F}$ \\
\hline BAC & F4? & $\mathrm{HAd}$ & HAC PÑ & $\mathrm{PD}^{*}$ ? & F5 & \\
\hline BAO-37 & $\mathrm{F} 4$ & i? 12-14 & $\begin{array}{l}\text { HAC PN } \\
\text { (PZ;?) }\end{array}$ & $\begin{array}{l}\text { 2BZ 3PD 4PD* } \text { DIL }^{*} \\
\text { COLL(32) }\end{array}$ & F3/F7 y F5ext & $\mathrm{F}$ \\
\hline FA-068 & CIL & $\mathrm{H} 20-30$ & HAC PN & $\mathrm{BZ}^{\star} \mathrm{PD}^{\star} \mathrm{COLL}(4)$ & F4/F4/F5/F7 & \\
\hline LC-A & MAM & & HAC PN & $\mathrm{BZ}^{*} 2 \mathrm{PD}^{2} \mathrm{PD}^{*} 2 \mathrm{PD}^{\circ}$ & $F ?$ & \\
\hline OF-037 & F4? & $i ? \mathrm{Ad}$ & HACext & $\operatorname{COLL}(i)$ & F4/F8a & $\mathrm{F}$ \\
\hline OF-205 & F4 & & HAC PN & & & \\
\hline OF-209 & F4 & $i ? \mathrm{Ad}$ & HAC & $\mathrm{PD} \mathrm{PD}^{*}$ & & \\
\hline OF-238 & F4 & $\mathrm{H} 40-60$ & HAC PN & BZ 2PD & & \\
\hline OF-244 & F4 & & HAC PN & $\mathrm{BZ}^{*} 2 \mathrm{PD}^{\star}$ & F7 & \\
\hline OF-278 & F4 & $\mathrm{H} ? 20-40$ & HAC PN & $2 \mathrm{PD}$ & F5 & \\
\hline TR-2 & FOS & $\mathrm{H} 24$ & HAC & COLL(?) & F2? & \\
\hline & & Otros & acimientos $-T u$ & bas dobles y triples & & \\
\hline BA-18 & F4 & $\begin{array}{l}\text { H } 22-29 \\
\text { H } 18-21 \\
\end{array}$ & HAC PÑ & $\mathrm{PD}^{*}$ & F2/F5ext & $\mathrm{F}$ \\
\hline BAO-52 & F4 & - & HAC 2PÑ & 2PD PD* COLL(43) & F2/F8/F1ext & \\
\hline CA-121 & cov & $\begin{array}{l}\mathrm{H} 27-29 \\
4\end{array}$ & HAC PÑ & 2BZ 3PD* COLL(3) & F3/F4/F4/F7 & $\mathrm{F}$ \\
\hline CE-18 & COV & $\begin{array}{l}\text { H 30-40 } \\
\text { F 25-35 } \\
\text { F 40-44 }\end{array}$ & HAC PÑ PZ & BZ COLL(1) & $\mathrm{F} 2 / \mathrm{F} 2 / \mathrm{F} 3 / \mathrm{F} 5$ & $\mathrm{~F}$ \\
\hline MM-17 & F4/F4 & $\begin{array}{l}i ?>35 \\
i ? 25-30\end{array}$ & HAC PÑ & COLL(?) & F8 & $\mathrm{F}$ \\
\hline OF-072 & $\mathrm{CIL}$ & - & HAC PÑ PZ & $2 \mathrm{PD}$ & F8a/F5ext & \\
\hline & & & notafios y tumba & problemáticas & & \\
\hline BA-13 & F2B3y & Cenotafio & HAC & & F5ext/F7ext & $F$ \\
\hline IF-2 & i? & ofing & HAC & & F5 & \\
\hline LC-B & CIL & - & HAC & $3{\mathrm{PD} P \mathrm{PD}^{*}}^{-}$ & $\mathrm{F}$ ? & \\
\hline
\end{tabular}

* Según métrica del contenedor funerario

Figura 3. 
Andúgar, L., Lull, V., Micó, R., Rihuete Herrada, C. y Risch, R. (2018-e.p.). Meat offerings in Argaric burials (South-East Spain, 2200-1550 cal BCE). En preparación.

Arribas, A., Craddock, P., Molina, F., Rothemberg, B. y Hоoк, D. R. (1989). Investigación arqueo-metalúrgica en yacimientos de las edades del Cobre y del Bronce en el sudeste de Iberia. En: Domergue, C. (ed.). Minería y metalurgia en las antiguas civilizaciones Mediterráneas y Europeas (vol. 1). Ministerio de Cultura. Madrid: 71-79.

Blance, B. (1971). Die Anfänge der Metallurgie auf der Iberischen Halbinsel. Studien zu den Anfänge der Metallurgie 4. Berlín.

Castro, P., Chapman, R. W., Gili, S., Lull, V., Micó, R., Rihuete Herrada, C., Risch, R. y Sanahuja, M. ${ }^{a}$ E. (1993-1994). Tiempos sociales de los contextos funerarios argáricos. Anales de Prehistoria y Arqueología de la Universidad de Murcia, 9-10: 77-105.

Delgado RaAcK, S. y Risch, R. (2008). Lithic perspectives on metallurgy: an example from Cooper and Bronze Age south-east Iberia. En: Longo, L. y Skakun, N. (eds.). Prehistoric Technology, 40 years later: Functional studies and the Russian legacy. BAR International Series 1783, Oxford, pp. 235-252.

Fregeiro, M. ${ }^{\text {a }}$ I. y Oliart, C. (2015). Los restos esqueléticos humanos de La Bastida procedentes de las campañas de excavación de los siglos XIX y XX. En: Lull, V., Micó, R., Rihuete, C. y Risch, R. (2015), Primeras investigaciones en La Bastida (1869-2005). Integral, Anexo 14. Murcia: 1471-1549.

Harrison, R. y Craddock, P. (1981). A study of the Bronze Age Metalwork from the Iberian Peninsula in the British Museum. Ampurias, 43: 113-179.

Hook, D. R., Arribas, A., Craddock, P. T., Molina, F. y Rothenberg, B. (1987). Copper and silver in Bronze Age Spain. En: Waldren, W. y Kennard, R. C. (eds.). Bell Beakers of the Western Mediterranean. British Archaeological Reports, 331. Oxford: 147-172.

Junghans, S., SAngmeister, E. y Schröder, M. (1960). Metallanalysen kupferzeitlicher und frü̈hbronzezeitlicher Bodenfunde aus Europa. Gebr. Mann, Berlín.

Junghans, S., Sangmeister, E. y Schröder, M. (1968). Kupfer und Bronze in der frühen Metallzeit Europas 1-3. Gebr. Mann. Berlín.

Kunter, M. (1990). Menschliche Skelettreste aus Siedlungen der El Argar-Kultur. Deutsches Archäologisches Institut, Philipp von Zabern. Maguncia.

Lull, V. (1983). La "cultura" de El Argar. Un modelo para el estudio de las formaciones económico-sociales prehistóricas. Akal. Madrid.
Lull, V. (2000a). Death and Society: A Marxist Approach. Antiquity, 74: 576-580.

Lull, V. (2000b) Argaric Society: Death at Home. Antiquity, 74: 581-590.

Lull, V. (2017), ¿De qué se ocupa la arqueología? MARQ - Arqueología y Museos, 8: 9-22.

Lull, V. y Estévez, J. (1986). Propuesta metodológica para el estudio de las necrópolis argáricas. En: Homenaje a Luis Siret (1934-1984). Junta de Andalucía. Sevilla: 441-452.

Lull, V. y Picazo, M. (1989). Arqueología de la muerte y estructura social. Archivo Español de Arqueología, 62: $5-20$.

Lull, V. y Risch, R. (1995). El Estado argárico. Verdolay, 7: 97-109.

Lull, V., Micó, R., Rihuete Herrada, C. y Risch, R. (2005). Property Relations in the Bronze Age of Southwestern Europe: an Archaeological Analysis of Infant Burials from El Argar (Almeria, Spain). Proceedings of the Prehistoric Society, 71: 247-268.

Lull, V., Micó, R., Rihuete Herrada, C. y Risch, R. (2009). El Argar: la formación de una sociedad de clases. En: Hernández Pérez, M., Soler, J. y López Padilla, J. A. (eds.). En los confines del Argar: una cultura del Bronce en Alicante en el centenario de Julio Furgús. Museo Arqueológico de Alicante. Alicante: 224-245.

Lull, V., Micó, R., Rihuete Herrada, C. y Risch, R. (2010). Metal and Social Relations of Production in the 3rd and 2nd Millennia BCE in the Southeast of the Iberian Peninsula. Trabajos de Prehistoria, 67 (2): 323-347.

Lull, V., Micó, R., Rihuete Herrada, C. y Risch, R. (2015a). Transcripción del diario de campo de la campaña de 1945 en La Bastida. En: Lull, V., Micó, R., Rihuete Herrada, C. y Risch, R. (2015). Primeras investigaciones en La Bastida (1869-2005). Anexo 5.2. Integral. Murcia.

Lull, V., Micó, R., Rihuete Herrada, C. y Risch, R. (2015b). La Bastida y Tira del Lienzo (Totana-Murcia). Integral. Murcia.

Lull, V., Micó, R., Rihuete Herrada, C. y Risch, R. (2016). Argaric Sociology: Sex and Death. Complutum, 27 (1): 31-62.

Lull, V., Micó, R., Rihuete Herrada, C., Risch, R., Celdrán, E., Fregeiro, M. ${ }^{a}$ I., Oliart, C. y Velasco, C. (2015c). La Almoloya (Pliego-Mula, Murcia). Integral. Murcia.

Lull, V., Micó, R., Rihuete Herrada, C., Risch, R. y Escanilla, N. (2017a). The absolute chronology of 
Argaric halberds. En: Barceló, J. A., Bogdanovic, I. y Morell, B. (eds.). IberCrono. Cronometrías Para la Historia de la Península Ibérica. CEUR-WS, Vol-2024 (urn:nbn:de:0074-2024-4). http://ceur-ws.org/Vol-2024/.

Lull, V., Micó, R., Rihuete Herrada, C., Risch, R. y Escanilla, N. (2017b). Halberdiers and combat systems in the Argaric. Oxford Journal of Archaeology, 36 (4): 375-394.

Lull, V, Micó, R., Rihuete Herrada, C. y Risch, R. (2017c). La metalurgia del cobre durante el Calcolítico y El Argar: un acercamiento desde los análisis químicos. En: García-Pulido, L. G., Arboledas Martínez, L., Alarcón García, E. y Contreras Cortés, F. (eds.). Presente y futuro de los paisajes mineros del pasado: Estudios sobre minería, metalurgia y poblamiento. Universidad de Granada. Granada: 203-214.

Martínez Rodríguez, A. y Ponce, J. (2002). Excavación arqueológica de urgencia en el subsuelo de la antigua iglesia del convento de las Madres Mercedarias (C/ Zapatería - C/ Cava, Lorca). Memorias de Arqueología, 10: $90-137$.

Molina, F., Rodríguez Ariza, M. ${ }^{a}$ O., Jiménez Brobeil, S. y Botella, M. (2003). La sepultura 121 del yacimiento argárico de El Castellón Alto (Galera, Granada). Trabajos de Prehistoria, 60 (1): 153-158.

Montero, I. (1994). El origen de la metalurgia en el sureste de la Península Ibérica. Instituto de Estudios Almerienses. Almería.

Montero, I., Martínez Rodriguez, A. y Ponce García, J. (2014). Nuevos datos sobre la metalurgia argárica en Lorca. Alberca, 12: 7-24.

Müller-Kissing, M. (2014). Neue Forschungen zur Chronologie und Metallurgie der El Argar-Kultur im Becken von Vera (Spanien). Archäologische Informationen, 37: 225-238. https://doi.org/10.11588/ ai.2014.0.18205

Murillo-Barroso, M., Montero, I. y Aranda, G. (2015). An insight into the organisation of metal production in the Argaric society. Journal of Archaeological Science, Reports 2 (2015): 141-155.

Pernicka, E. (1998). Die Ausbreitung der Zinnbronze im 3. Jahrtausend. En: B. Hänsel (Hrsg.). Mensch und Umwelt in der Bronzezeit Europas - Man and Environment in European Bronze Age, Abschlußtagung: Die Bronzezeit, das erste goldene Zeitalter Europas, Berlin, 17.-19. März 1997. Kiel: 135-147.

Pingel, V., Schubart, H., Arteaga, O. y Kunst, M. 1998. Fuente Álamo: Vorbericht über die Grabung 1996 in der bronzezeitlichen Höhensiedlung. Madrider Mitteilungen, 39: 14-34.
Posac, C., Sopranis, J. A. y del Val, E. (1947). Las sepulturas. En: Martínez Santa-Olalla, J., Sáez Martín, B., Posac, C., Sopranis, J. A. y del Val, E. Excavaciones en la ciudad del Bronce Mediterráneo II de La Bastida de Totana. Ministerio de Educación Nacional, Informes y Memorias $n^{\circ} 16$. Madrid.

Risch, R. (2002). Recursos naturales, medios de producción y explotación social. Un análisis económico de la industria lítica de Fuente Alamo (Almería), 22501400 ANE, Iberia Archaeologica. Philipp von Zabern. Maguncia.

Rovira, S., Montero, I. y Consuegra, S. (1997). Las Primeras etapas metalúrgicas en la península Ibérica. I. Análisis de Materiales. Instituto Universitario y Fundación Ortega y Gasset. Ministerio de Educación y Cultura. Madrid.

Schubart, H. (1973). Las alabardas tipo Montejícar. En: Maluquer de Motes, J. (ed.). Estudios dedicados al Profesor Dr. Luis Pericot. Universidad de Barcelona. Barcelona: 247-269.

Schubart, H. (2012). Die Gräber von Fuente Álamo. Ein Beitrag zu den Grabriten und zur Chronologie der El Argar-Kultur. Madrider Beiträge 32, Deutsches Archäologisches Institut Madrid. Reichert Verlag. Wiesbaden.

Schubart, H. y Arteaga, O. (1986). Fundamentos arqueológicos para el estudio socio-económico y cultural del área de El Argar. En: Homenaje a Luis Siret. Junta de Andalucía. Sevilla: 289-307.

Simón García, J. L. (1998). La Metalurgia Prehistórica Valenciana. Serie de Trabajos Varios 93. Servicio de Investigación Prehistórica. Diputación Provincial de Valencia. Valencia.

Siret, H. y Siret, L. (1888). Les Premiers âges du métal dans le Sud-Est de l'Espagne. Révue des Questions Scientifiques, XVI: 5-110.

Siret, H. y Siret, L. (1890). Las primeras edades del metal en el sudeste de España. Sucesores de N. Ramírez. Barcelona.

SPINDLER, K. (1971). Zur Herstellung der Zinnbronze in der frühen Metallurgie Europas. Acta Praehistorica et Archaeologica, 2: 199-253.

Val, E. del y Sopranis, J. A. (2015). Diario de campo de la campaña de 1945 en La Bastida. En: Lull, V., Micó, R., Rinuete, C. y Risch, R. (2015), Primeras investigaciones en La Bastida (1869-2005). Anexo 5.1. Integral. Murcia.

Woolley, L. (1934). Ur Excavations. The Royal Cemetery. British Museum \& Museum of the University of Pennsylvania. Oxford. 